\title{
A study of the H-reflex by single fibre EMG
}

\author{
J. V. TRONTELJ \\ From the Institute of Clinical Neurophysiology, \\ The University Hospitals, Ljubljana, Yugoslavia
}

SUMMARY The latency of consecutive H-reflex responses of single human triceps surae motoneurones varies up to $2,500 \mu \mathrm{s}$. A large part of this variation was shown to occur at the synaptic transmission. A moderate increase in stimulus strength from the threshold value shortened the mean latency and reduced the latency variation, presumably as a result of spatial summation of excitatory inputs. Further increase to maximum strength lengthened the mean latency, increased the variation, and resulted in a dropping out of some responses which was not produced by collision by antidromic impulses. These effects are believed to be due to an active inhibition. Changes of the latency were also obtained by Jendrassik's manoeuvre and facilitatory and inhibitory conditioning stimuli.

With a few exceptions, the H-reflex has so far not been studied in man at the level of single motor neurones. The obvious advantage of such studies is that they can reveal information which tends to be masked by interference of the responses of different motoneurones, when recording the reflex from a population of motor units. As noted by Lloyd (1956),

'questions arise from time to time concerning the behaviour of motoneurones in some circumstances of reflex activation that cannot be answered by observation of a population of motoneurones. It is then appropriate to resort to the study of individual members of the population. Even without the pressure of necessity it sometimes happens that the observation of individuals increases one's grasp of the population's workings'.

Indeed, a large part of our present knowledge of the monosynaptic reflexes has been gathered by studying single cat motoneurones. The recent development of single fibre electromyography (EMG) (Ekstedt, 1964; Stålberg, 1966; Ekstedt and Stålberg, 1969) has made possible such studies in intact man (Trontelj, 1968). It has already been shown that there is a considerable variation in the latency of successive $\mathrm{H}$-responses of single motoneurones, a part of which is due to the variation in the synaptic delay (Trontelj, 1969) and which can be changed by a modification in the synaptic input (Trontelj, 1970). The present work extends these findings.

\section{METHOD}

An H-reflex was elicited in the calf muscles by stimulating the tibial nerve in the popliteal fossa. The stimuli were rectangular electrical pulses, lasting 10,25 , or $50 \mu \mathrm{s}$, and delivered through a needle electrode (Disa 13K23), which was introduced close to the nerve, so that the threshold for the reflex response was as low as 1-5 V. Surface stimulating electrodes (Disa 13K62) were also used in a few cases. The rate of stimulation was never higher than $0 \cdot 3 / \mathrm{s}$ in order to minimize changes of synaptic efficacy (Curtis and Eccles, 1959). The responses of the population of motor units were detected by pairs of silver-silver chloride cup electrodes attached to the skin over the medial gastrocnemius and the soleus muscles. The responses of single muscle fibres were picked up by a specially designed needle electrode (Ekstedt et al., 1969), amplified, and displayed on a Tektronix 565 oscilloscope with a $2 \mathrm{~A} 61$ or $3 \mathrm{~A} 9$ amplifier. The criterion used to identify the action potentials as being generated by single muscle fibres was that, under recording conditions with time resolution of at least $10 \mu \mathrm{s}$, consecutive potentials were of identical shape (Ekstedt, 1964; Ekstedt and Stålberg, 1969). On threshold stimulation, such responses always followed the all-or-nothing principle.

It was usually easy to identify individual motor neurones according to the amplitude, shape, and duration of muscle fibre action potentials, as well as according to their latencies and thresholds. This was particularly so when the recording was made from two or more muscle fibres pertaining to the same 951 


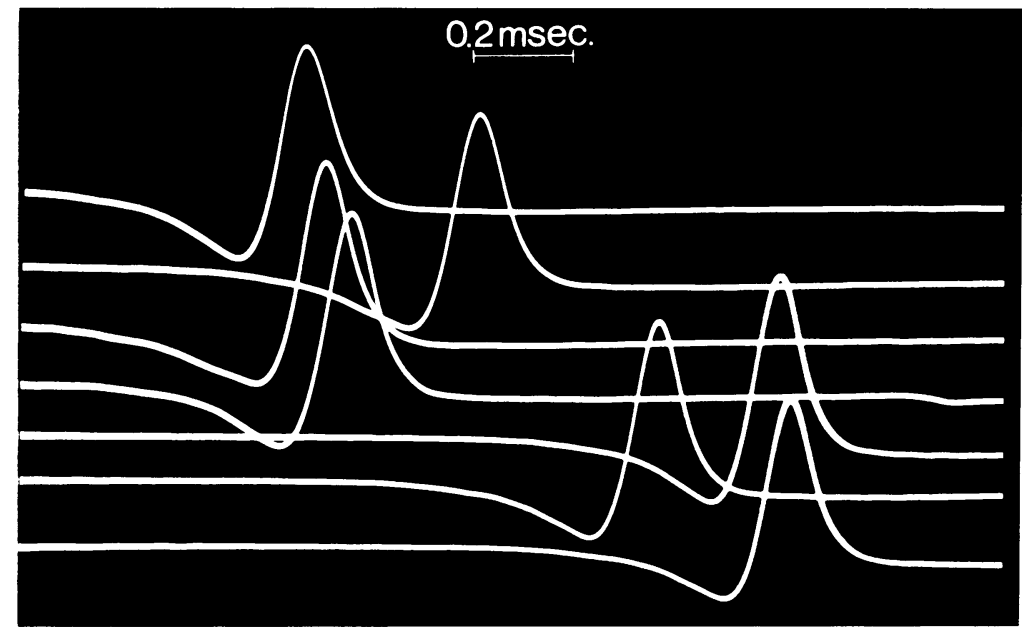

FIG. 1. H-responses of $a$ single muscle fibre, elicited at a rate of $0 \cdot 3 / s$. The traces were delayed 31 ms after the stimulus.

occurrence of these potentials and by the small changes in interpotential intervals. However, in certain circumstances, particularly when stronger stimuli were used, another criterion had to be applied : that no potentials of similar amplitude, shape, and duration, generated by muscle fibres of neighbouring motor units, were present in the tracing. These criteria allowed not only reliable identification of the individual motor neurones but also high accuracy of latency measurements (better than $10 \mu \mathrm{s}$ ).

The latencies were measured to a selected amplitude point of the steep part of the action potential automatically by a specially constructed hybrid computer unit and fed into an HP 2114B computer for on-line statistical analysis. The time unit was 5,8 , or $10 \mu s$. All the experiments were also recorded on a magnetic tape recorder (PI 6200) and some were analysed offline.

Surface-detected reflex responses of the soleus muscle were rectified and integrated with an originally designed unit and fed into the computer to be crosscorrelated with the latencies.

The experiments were performed in 30 healthy volunteers, 20 to 25 years old, and in a 20 year old patient with a clinically complete transverse division of the spinal cord at C5 segment of 16 months' duration.

\section{RESULTS}

A spontaneous latency variation of more than 400 us was obtained for all motoneurones from which at least 100 responses were recorded. The largest variation exceeded 2,000 us, but in over $90^{\circ}$ of the motor neurones it was between 500 and 2.000 us (Fig. 1).

The distribution of the latencies was more o: less Gaussian in most cases, except that it was sometimes slightly skewed toward the longe $\overrightarrow{-}$ latencies. In four cases, however, a clear-cu遇 bimodal distribution was found, with a freg $\frac{\mathbb{D}}{3}$ interval of 1,500 to $3,000 \mu \mathrm{s}$ between the tw? peaks (Fig. 2). Changes in stimulus strength and frequency and the performance of Jendrassik manoeuvre had no visible effect on the occurrence $\omega$ of the early or late responses.

Except for these particular cases, changes in stimulus strength strongly influenced the latencies; in general, weak stimuli produced responses with longer latencies and a larger latency dispersion than did strong stimuli.

In a series of experiments, H-reflexes of $\frac{3}{2}$ individual motoneurones were elicited with stimuli of three different strengths: threshold strength, at which about half of the stimuli $\frac{\partial}{0}$ produced a reflex response; maximum strength, at which about half of the reflex responses were $\underline{3}$. replaced by direct responses of the same mo- o toneurone; and intermediate strength, which was the mean of the former two values. Attempts 옥 were also made to measure the latency variation $\frac{7}{2}$ of direct responses of the same motoneurones at two stimulus strengths, threshold and well above $\widetilde{N}$ threshold. This was sometimes not possible N because of the interference of other motor units. స్ట 


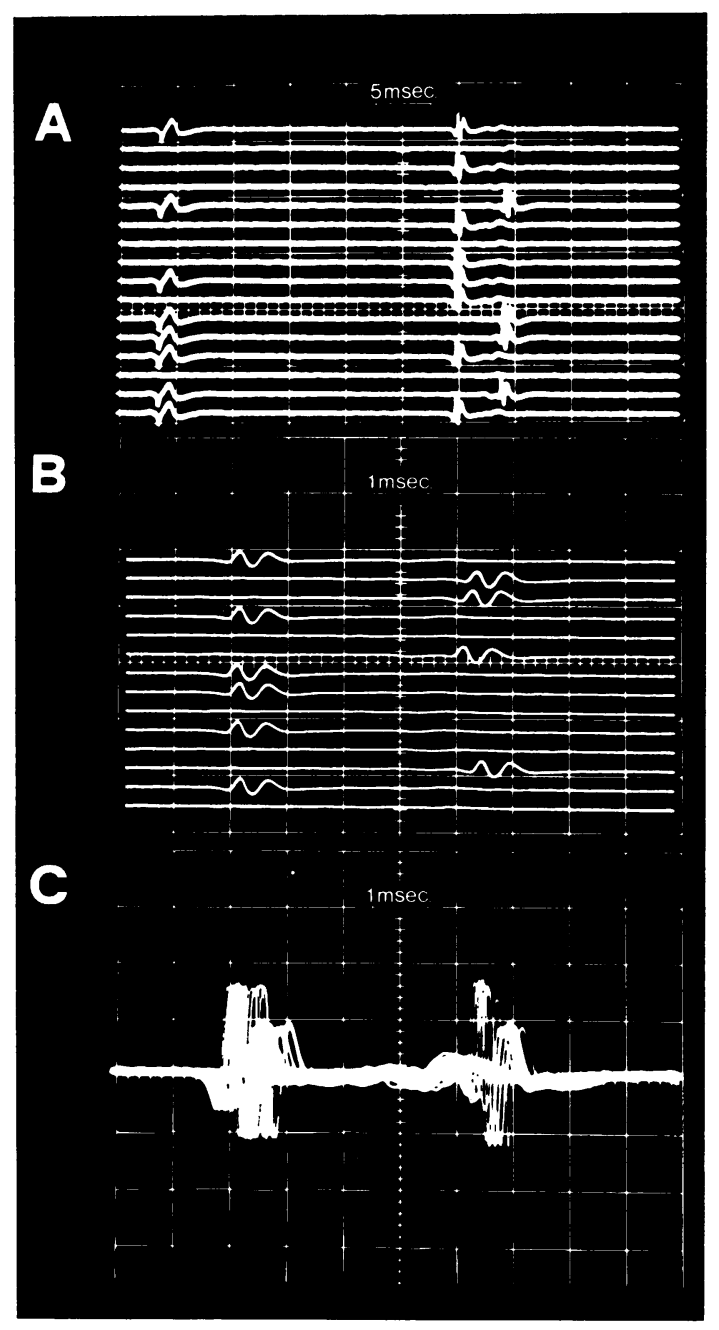

FIG. 2. H-responses of a motoneurone represented in the recording by two muscle fibres. The latencies show bimodal distribution. The traces were delayed $28.9 \mathrm{~ms}$ after the stimulus in $\mathrm{B}$ and $\mathrm{C}$.

Series of 100 responses were assessed at each stimulus strength at a repetition rate of 1 per $3 \mathrm{~s}$. The results are summarized in Fig. 3.

When increasing the strength of the stimulus from threshold to the intermediate value, there was always a shortening of the mean latency (significant at a level of $\mathrm{P}<0.001$ in 23 out of 25 motoneurones), while the jitter (standard deviation) always decreased (by an average of $70 \%$ ). Further increasing the stimulus strength to the

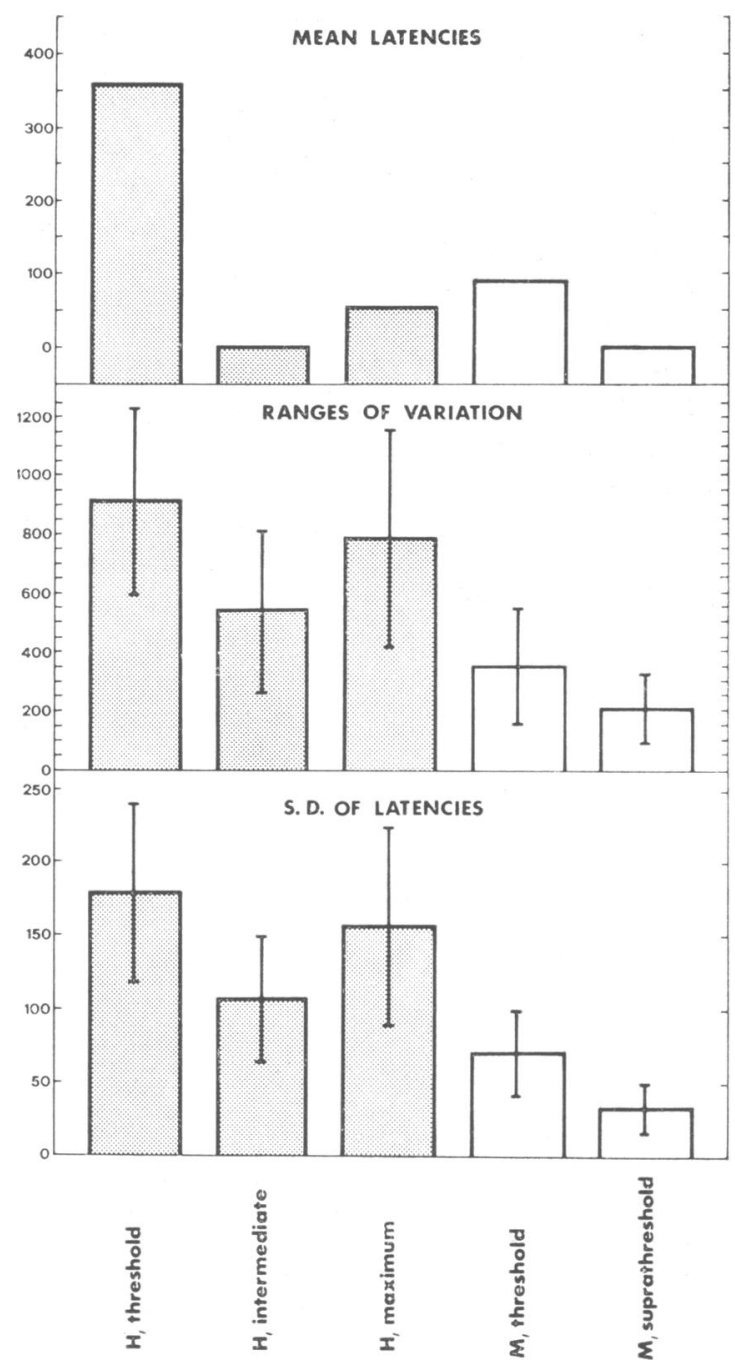

FIG. 3. Dependence of latency of the $M$ and $H$ responses and of latency dispersion on stimulus strength. The data are means of values from $25(\mathrm{H})$ and 15 (M) motoneurones, each obtained from 100 consecutive responses for each stimulus strength. Mean latencies are expressed as increase in reference to the mean latency obtained at intermediate $(\mathrm{H})$ and suprathreshold (M) stimulus strength, respectively.

maximum for reflex response, however, resulted in a lengthening of the mean latency (significant in 12 out of 25 motoneurones) and in an increase in the jitter (by an average of $66 \%$ ). Only eight out of 25 motoneurones showed further significant shortening of the latencies, and only 
four (three of which belonged to the former eight) exhibited a decrease of the jitter. The increase in stimulus strength from intermediate to maximum was followed by an increase in the surface-detected responses in eight out of these nine cases, whereas it produced a decrease in 14 of the remaining 16 cases.

At maximum stimulus strength, there was an irregular alternation of reflex and direct responses of individual motoneurones. But in 16 out of the 25 motoneurones some stimuli failed to elicit any response, although at the intermediate - that is, lower stimulus strengththere was no failing of the responses. The remaining nine motoneurones were those which exhibited shortening of the latencies and/or decrease of the jitter when the stimulus strength was increased from intermediate to maximum.

The intermittent failure of the responses, larger latency dispersion, and the lengthening of the mean latency at maximum stimulus strength persisted when the interval between the stimuli was increased from 3 to $10 \mathrm{~s}$. Increases of stimulus strength had the same effects in three motoneurones of a paraplegic patient with a complete division of the spinal cord.

At all stimulus strengths there was some degree of variation in the size of surface-detected responses - that is, of the size of the participating population of motoneurones. There was a significant negative cross-correlation between the size of the responding population and the latencies of the individual motoneurones $(r=$ $-0 \cdot 44, \mathrm{P}<0 \cdot 001)$.

The direct responses had a considerably smaller jitter than the reflex responses of the same motoneurones. The increase in stimulus strength from threshold to suprathreshold

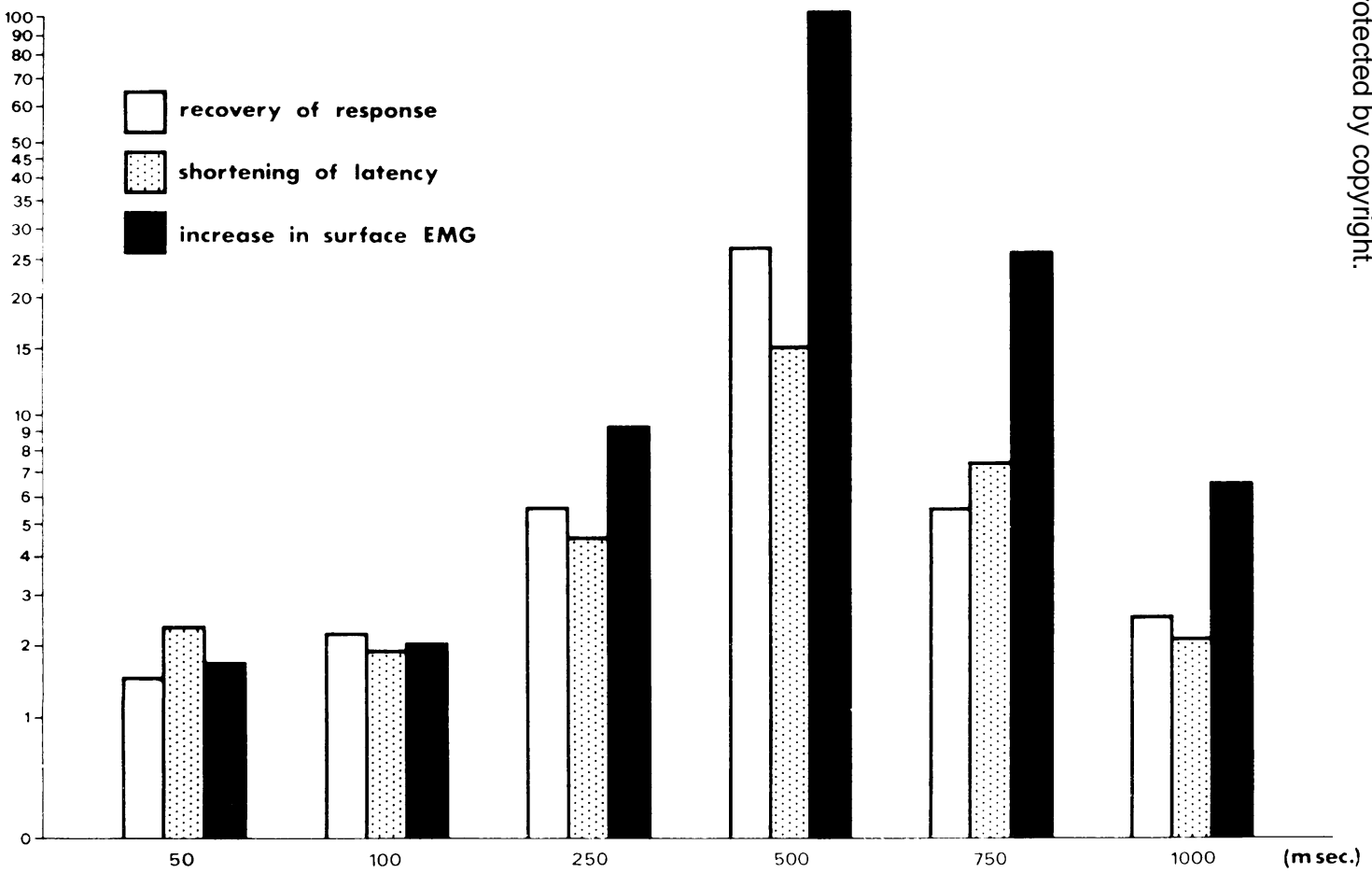

FIG. 4. Effects of Jendrassik's manoeurre at different intercals between command and stimulus. Results are shown as ratios of the expected effects-that is, recovery of previously absent response (white columns), shortening of the latency (dotted columns), and increase in surface-detected EMG (black columns) versus contrary, or paradoxical effects. The data represent averages of four different motoneurones, with 200-400 responses being computed for each interval. Notice logarithmic scale. 


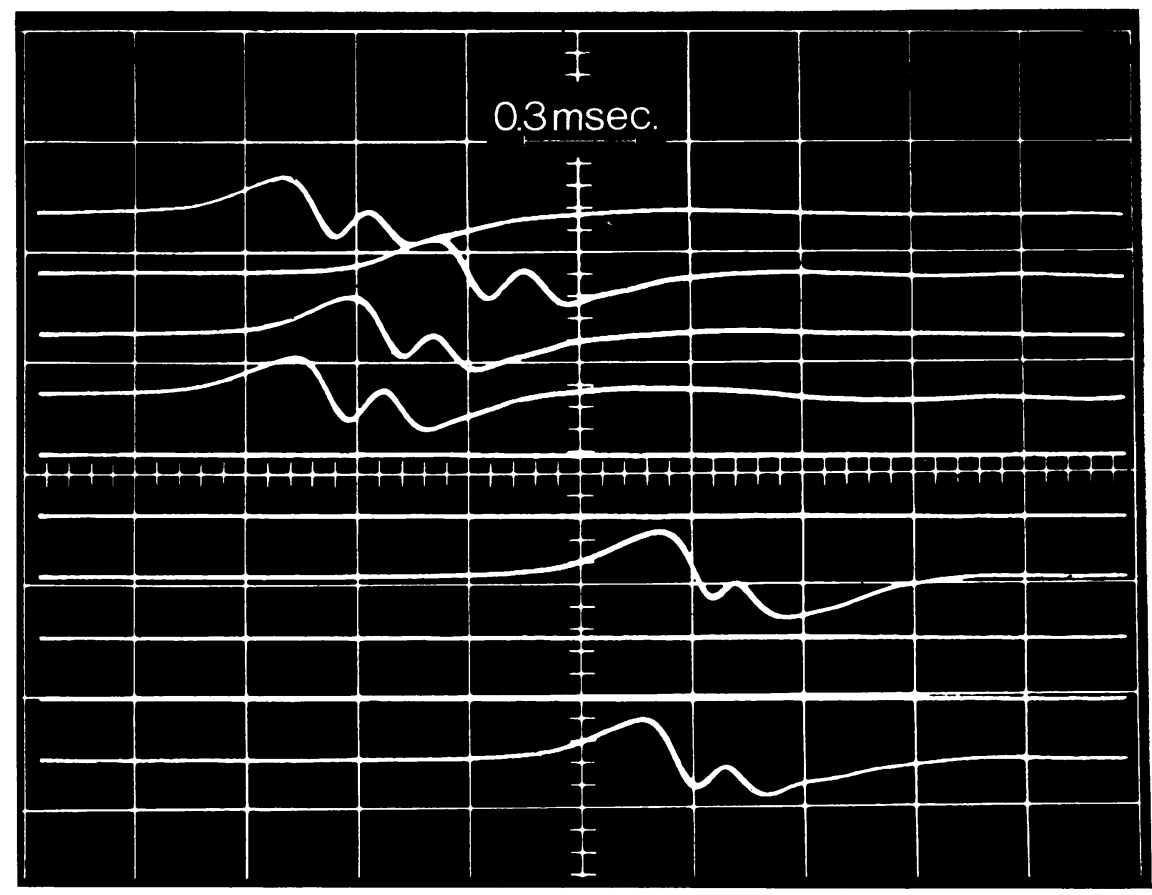

FIG. 5. Shortening of the latency of H-responses of a motoneurone (two muscle fibres) obtained by applying a conditioning pulse to the peroneal nerve at a $50 \mathrm{~ms}$ testing interval (upper four traces). The traces were delayed $37.5 \mathrm{~ms}$ after the stimulus.

resulted in a decrease of the jitter by an average of $56 \%$.

In general, there was no significant crosscorrelation between the latencies of the direct responses and the size of the population activated in the reflex responses. In a few cases, however, the latencies of the direct responses obtained with threshold stimulation were positively correlated with the size of the reflexly activated population.

Latency of the H-reflex of individual motoneurones was influenced by a variety of conditioning stimuli and manoeuvres. It could be shortened by slight voluntary activation of the triceps surae that was subthreshold for the tested motoneurone, by Jendrassik's manoeuvre, by a subthreshold conditioning stimulus to the tibial nerve preceding the testing stimulus by $0 \cdot 5-$ $1 \mathrm{~ms}$, and particularly by a conditioning stimulus to the peroneal nerve at a testing interval of 40-60 ms. On the other hand, it could be lengthened by passive stretch of the triceps surae, by voluntary activation of the anterior tibial muscle, by a subthreshold conditioning stimulus to the tibial nerve at intervals between $1 \mathrm{~ms}$ and $1 \mathrm{~s}$, and by a conditioning stimulus to the peroneal nerve at intervals of $20-40 \mathrm{~ms}$. The latter methods resulted in an increase in the allor-none threshold for the reflex responses, while those which shortened the latency also decreased the threshold.

The effects of Jendrassik's manoeuvre and of stimulating the peroneal nerve were studied in somewhat more detail. It was observed that the effect of Jendrassik's manoeuvre depended on the interval between the visual or auditory signal informing the subject to start the manoeuvre (clench the contralateral fist for $1 \mathrm{~s}$ ) and the testing stimulus. Six intervals $(50,100,250,500$, 750 , and $1,000 \mathrm{~ms}$ ) were tested in each of four motoneurones of different subjects. Incomplete experiments with less than six testing intervals 


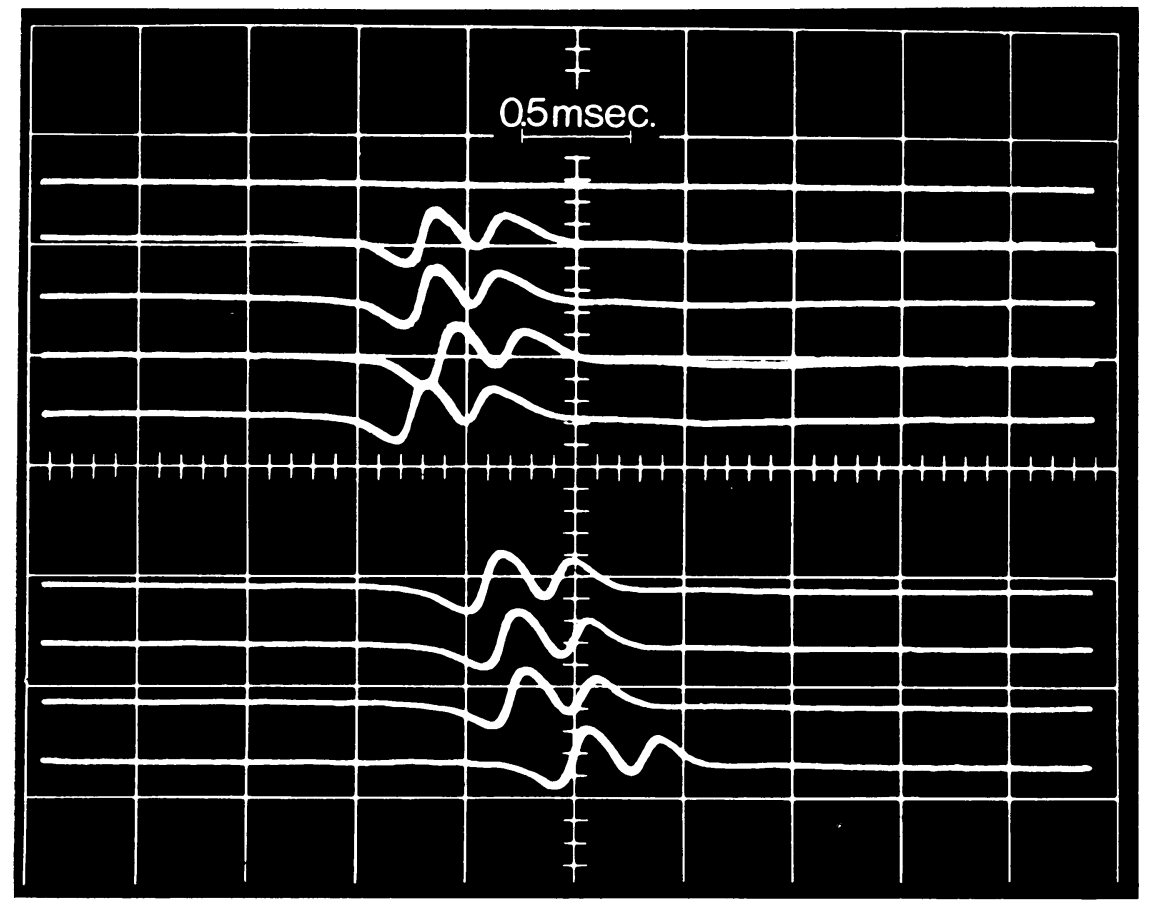

FIG. 6. Lengthening of the latency of H-responses of a motoneurone (pair of muscle fibres) obtained by applying a conditioning stimulus to the peroneal nerve at a $30 \mathrm{~ms}$ testing intercal (lower four traces). The traces were delayed $30.5 \mathrm{~ms}$ after the stimulus.

were performed in an additional six motoneurones. The stimuli preceded by Jendrassik's manoeuvre and the control stimuli were presented in a random sequence to avoid the subject's anticipation of the manoeuvre. The EMG of finger flexors was monitored and, whenever the delay after the commanding signal exceeded $250 \mathrm{~ms}$, a slightly painful warning electrical stimulus was applied with a view to achieving the fastest possible reactions. Every interval was tested with $200-400$ stimuli at a rate of one per $3 \mathrm{~s}$.

The results in four motoneurones are shown in Fig. 4. Even at the most effective interval tested, $500 \mathrm{~ms}$, Jendrassik's manoeuvre did not consistently shorten the latency of the response. The superimposed spontaneous depression, which frequently lasted about $10 \mathrm{~s}$, was occasionally stronger and resulted in prolongation of the latency or even a failure to respond in spite of the facilitation produced by the manoeuvre. In a single series of 200 responses, the maximum average shortening of latencies was 239 us. The effects were most pronounced when stimulus strength was slightly above the threshold for the reflex response of the observed motoneurone and were nearly absent at very strong stimuli. Similar results were obtained in the remaining six motoneurones not included in Fig. 4. In all motoneurones, Jendrassik's manoeuvre was clearly effective at testing intervals of 250 and $100 \mathrm{~ms}$, in most even at $50 \mathrm{~ms}$.

Considerably stronger effects were obtained by stimulating the peroneal nerve with a single pulse, 50 us in duration, 40 to $60 \mathrm{~ms}$ before the test stimulus. The conditioning stimulus had to be above the motor threshold. The shortening of latencies was of the order of 200-500 us. but the extreme values for some series were as high as $1,000-1,500$ us (Fig. 5). Comparable lengthening could be produced at testing intervals between 20 and $30 \mathrm{~ms}$ (Fig. 6). 


\section{DISCUSSION}

It is possible to distinguish between three types of latency changes of the H-reflex of individual motoneurones as observed in this study: first, the 'spontaneous', more or less random variation from response to response, which is referred to as the 'jitter' of the reflex; second, the systematic shortening or lengthening produced by a change in the experimental conditions; and third, the slow, 'spontaneous' shifts randomly superimposed upon the former two and accompanied by a change in the all-or-none threshold.

As has been suggested (Trontelj, 1968; 1969; 1970), a considerable part of the reflex jitter must be due to variation in the synaptic delay that results from changes in experimentally uncontrolled synaptic inputs to the motoneurone under study and, perhaps, from some other changes in its firing threshold. When controllable experimental conditions were kept as constant as possible, the jitter of reflex responses was found to depend on stimulus strength, being largest at threshold strength and smallest at intermediate strength.

That jitter is related to variation in the synaptic input is also suggested by the finding that there was a significant negative correlation between the latency of individual motoneurones and the size of the responding population. The coefficient of correlation was even higher when the synaptic input was varied by changing stimulus strength or introducing conditioning inputs from the periphery and supraspinal levels.

In addition to synapses, other segments of the reflex arc may contribute to the jitter of the $\mathrm{H}$ reflex. In our experimental conditions, the motor end plate and the stimulated point of the afferent nerve fibres are likely to be sources of variation. The jitter of neuromuscular transmission is normally less than 30-40 $\mu \mathrm{s}$ (Stålberg et al., 1971), but it is not known how much of the total jitter is due to variations in the Ranvier nodes along the length of the afferent nerve fibres at which the propagated action potentials start. The total contribution of both factors can be estimated roughly from the latency variation of direct responses of the studied single motoneurones, if it is assumed that afferent and motor nerve fibres do not differ in regard to the initiation of the propagated action potentials at the site of stimulation.

It is not likely that other sections of the reflex arc contribute significantly to the jitter. As has already been reported (Stålberg and Trontelj, 1970), when stimulus strength is increased from threshold values to well above threshold, the latency of direct responses shortens and the jitter is reduced. Presumably the shortening of the latency is due to a shift in the starting point of the propagated action potentials away from the stimulating electrode (cf. Wiederholt, 1969) to a more distal node of Ranvier, and the decrease of the jitter is thought to result from a steeper time course of the local response of the node (cf. Del Castillo and Stark, 1952).

The reflex responses changed in a similar manner when the stimulus strength was increased from threshold to the intermediate value. However, the diminution of the jitter was about twice as large and the shortening of the mean latency four times as large as that of the direct responses. This difference can probably be attributed to synaptic events: an increased slope of motoneuronal excitatory post-synaptic potential (EPSP) due to the activation of additional afferent terminals, resulting in earlier and more stable triggering of the propagated spike potential.

It might be argued that the amount of latency changes attributed to variation in the synaptic delay exceeds the synaptic delay itself and even the total intraspinal delay reported for the monosynaptic reflexes both in the cat and in man (Lloyd, 1943; Magladery et al., 1951). However, monosynaptic reflexes recorded intracellularly from cat motoneurones do show appreciable jitter, which may, in some circumstances, substantially exceed $500 \mu$ s, particularly when threshold stimulation is used (cf. Coombs et al., 1955, Fig. 4D). The jitter is due to uncertainty in the triggering of the propagated spike potential from the EPSP, while the EPSP itself exhibits only a negligible jitter in these recordings. In other words, the firing threshold of the motoneurone seems to fluctuate randomly within a certain range of membrane potential values. The jitter of the reflex depends on the length of the EPSP's course through the range of threshold, hence on the steepness of the EPSP's rising slope in that range. With spatial summation 
of the afferent inflow, the EPSP becomes steeper, the jitter is reduced, and the latency is shortened. The shortening may exceed $1,000 \mu$ s (cf. Eccles, 1957, Fig. 14). The maximum shortening of the mean latency obtained in this study by increasing stimulus strength exceeded $1,500 \mu \mathrm{s}$. However, the shortest and longest latencies of single responses differed by more than $3,000 \mu \mathrm{s}$.

Using various methods to facilitate and inhibit the H-reflex, it has been confirmed that the main part of the observed latency changes, perhaps as much as 80 to $90 \%$, is due to synaptic mechanisms. Shortening quite comparable with that obtained by increasing stimulus strength was achieved by applying a conditioning stimulus to the peroneal nerve 40 to $60 \mathrm{~ms}$ before the test stimulus, a method which is known to facilitate the H-reflex strongly (Park et al., 1951) Jendrassik's manoeuvre was a little less effective, but it still could shorten the mean latency by more than $300 \mu \mathrm{s}$. The interval between the command and the test stimulus was found to be more important than the muscular force developed in the manoeuvre. The most effective intervals were 500 and $750 \mathrm{~ms}$, but some effects were seen at 100 and even 50 ms-that is, even more than $100 \mathrm{~ms}$ before EMG activity appeared in the finger flexors. This indicates that rather fast descending pathways must have been involved. The very small effects of Jendrassik's manoeuvre seen at strong stimuli suggest that any of the observed motoneurones could be nearly maximally excited by the $\mathrm{H}$-reflex stimulus.

The amount of latency changes observed in this study suggests that the EPSP of the H-reflex, or at least its course through the region of the triggering threshold, must be less steep and considerably longer than in the cat.

Surprisingly, when stimulus strength was further increased from the intermediate value to the maximum strength for the reflex response, a reverse change occurred in most motoneurones: the jitter again increased and the mean latency lengthened. It is difficult to explain these results except as reflecting the effect of activating inhibitory synapses. An additional evidence for the role of inhibition is provided by the finding that, at maximum stimulus strength, some stimuli were followed by neither reflex nor direct responses; failing of reflex responses was thus not due to collision with antidromic impulses but could be due only to active inhibition. The threshold for this inhibition seems to be comparatively high, as it was manifested only at higher stimulus strength, and was not manifested at all in motoneurones with a low maximum stimulus strength for reflex responses. At this stimulus strength, the maximum population response was not yet reached.

An interesting feature of this inhibition is its early appearance: at least certain motoneurones must have been reached by excitatory and inhibitory volleys practically simultaneously. This raises the following problem: if the electrical threshold of the inhibitory fibres is higher than that of the excitatory ones, then their conduction velocity should be lower. This is indeed the case for Ib fibres in the cat (Eccles et al., 1957a). Besides, the inhibitory pathways should contain at least one interneurone that would introduce an additional delay. Both of these considerations also speak against heteronymous recurrent inhibition as a possible explanation for the observed depression of the reflex at the maximum stimulus strength.

Even in the cat, however, both $\mathrm{Ib}$ and re-current inhibition can occur rather early (Eccles, $\varnothing$ 1967). Ib fibres activated by stronger stimuli give rise to an inhibitory post synaptic potentialo (IPSP) superimposed on the EPSP with a small? delay of $1 \mathrm{~ms}$ or less (cf. Eccles et al., 1957b, Figs 1 and 2) and may depress the EPSP even before it reaches its peak. Recurrent inhibition, too, can occur rather early in the cat, and its latency of $1.2 \mathrm{~ms}$ does not essentially exceed that of the EPSP (Eccles, 1955). The $\alpha$-motoneurones in the human tibial nerve are believed to conduct considerably more slowly than Ia fibres (Magladery et al., 1951; Diamantopoulos and Gassel, 1965); however, there is certain evidence that at least some motoneurones conduct as fast as Ia fibres converging upon them, as it is possible to obtain both direct and reflex responses of the same motoneurone to one stimulus (Trontelj, 1973).

It could also be argued that the inhibitory effect is not produced by the same stimulus but by the preceding one. The interval of $3 \mathrm{~s}$ may be too long for an inhibition of segmental origin but might be appropriate for a long-loop inhibitory reflex involving supraspinal structures. This possibility could not be ruled out completely; 
however, persistence of inhibition when the interval was increased to $10 \mathrm{~s}$ and the results obtained from the patient with a complete transverse spinal lesion indicate that it cannot be the only explanation.

If the observed effects are to be attributed to Ib fibres or to recurrent inhibition, the relatively high threshold of these effects need not be due to the higher threshold and lower conduction velocity of Ib fibres and motor axons, but might as well be explained as a result of their smaller number or weaker synaptic efficacy. Consequently, a stronger stimulus would be needed to activate' a sufficient number.

On the other hand, the excitatory impulses too may be mediated through an interneurone. The two-peak latency distribution observed in some motoneuronescan best be explained byalternative monosynaptic and disynaptic activation.

Finally, the duration of the H-reflex EPSP in man seems to be considerably longer than in the cat. Its course through the range of firing threshold can be longer than $2,000 \mu \mathrm{s}$. So, even an inhibitory volley delayed $2 \mathrm{~ms}$ after the excitatory volley could effectively suppress the response.

\section{REFERENCES}

Coombs, J. S., Curtis, D. R., and Eccles, J. C. (1957). The generation of impulses in motoneurones. Journal of Physiology, 139, 232-249.

Coombs, J. S., Eccles, J. C., and Fatt, P. (1955). Excitatory synaptic action in motoneurones. Journal of Physiology, 130, 374-395.

Coquery, J. M., Mark, R. F., and Paillard, J. (1962). Les fluctuations spontanées du réflexe de Hoffmann à différents niveaux de la courbe de recrutement. Electroencephalography and Clinical Neurophysiology, Suppl. 22, 90-92.

Curtis, D. R., and Eccles, J. C. (1959). Repetitive synaptic activation. Journal of Physiology, 149, 43P-44P.

Del Castillo, J., and Stark, J. (1952). Local responses in single medullated nerve fibres. Journal of Physiology, 118, 207215.

Diamantopoulos, E., and Gassel, M. M. (1965). Electrically induced monosynaptic reflexes in man. Journal of Neurology, Neurosurgery, and Psychiatry, 28, 496-502.

Eccles, J. C. (1955). The central action of antidromic impulses in motor nerve fibres. Pflïgers Archiv für die gesamte Physiologie des Menschen und der Tiere, 260, 385-415.

Eccles, J. C. (1967). The inhibitory control in spinal reflex action. Electroencephalography and Clinical Neurophysiology, Suppl. 25, 20-34.
Eccles, J. C., Eccles, R. M., and Lundberg, A. (1957a). Synaptic actions on motoneurones in relation to the two components of the group I muscle afferent volley. Journal of Physiology, 136, 527-546.

Eccles, J. C., Eccles, R. M., and Lundberg, A. (1957b). Synaptic actions on motoneurones caused by impulses in Golgi tendon organ afferents. Journal of Physiology, 138, 227-252.

Ekstedt, J. (1964). Human single muscle fiber action potentials. Acta Physiologica Scandinavica, 61, Supplement 226.

Ekstedt, J., Häggqvist, P., and Stålberg, E. (1969). The construction of needle multi-electrodes for single fiber electromyography. Electroencephalography and Clinical Neurophysiology, 27, 540-543.

Ekstedt, J., and Stålberg, E. (1969). The effect of nonparalytic doses of D-tubocurarine on individual motor endplates in man, studied with a new electrophysiological method. Electroencephalography and Clinical Neurophysiology, 27, 557-562.

Lloyd, D. P. C. (1943). Conductjon and synaptic transmission of reflex response to stretch in spinal cats. Journal of Neurophysiology, 6, 317-326.

Lloyd, D. P. C. (1956). Monosynaptic reflex response of individual motoneurons as a function of frequency. Journal of General Physiology, 40, 435-450.

Magladery, J. W., Porter, W. E., Park, A. M., and Teasdall, R. D. (1951). Electrophysiological studies of nerve and reflex activity in normal man. IV. The two-neurone reflex and identification of certain action potentials from spinal roots and cord. Bulletin of the Johns Hopkins Hospital, 88, 499-519.

Park, A. M., Teasdall, R. D., and Magladery, J. W. (1951). Electrophysiological studies of nerve and reflex activity in normal man. VII. Certain effects of brief stretch. Bulletin of the Johns Hopkins Hospital, 88, 549-561.

Stålberg, E. (1966). Propagation velocity in human muscle fibers in situ. Acta Physiologica Scandinavica, 70, Supplement 287.

Stålberg, E., Ekstedt, J., and Broman, A. (1971). The electromyographic jitter in normal human muscles. Electroencephalography and Clinical Neurophysiology, 31, 429-438.

Stålberg, E., and Trontelj, J. V. (1970). Demonstration of axon reflexes in human motor nerve fibres. Journal of Neurology, Neurosurgery, and Psychiatry, 33, 571-579.

Trontelj, J. V. (1968). H-reflex of single motoneurones in man. Nature, 220, 1043-1044.

Trontelj, J. V. (1969). Latency variation of single human motoneurones in the H-reflex. (abstract.) Electroencephalography and Clinical Neurophysiology, 27, 723.

Trontelj, J. V. (1970). Reflex facilitation and inhibition of single motoneurones in man. Iugoslavica Physiologica et Pharmacologica Acta, 6, 119-124.

Trontelj, J. V. (1973). A study of the F-wave by single fibre EMG. In New Developments in Electromyography and Clinical Neurophysiology, pp. 318-322. Edited by J. E. Desmedt. Vol. 3. Proceedings of the 4th International Congress on Electromyography, Brussels, 1971. Karger: Basel.

Wiederholt, W. C. (1969). Threshold and conduction velocity in human median nerve sensory fibers. (abstract.) Electroencephalography and Clinical Neurophysiology, 27, 718. 